\title{
Applying Logistic Regression on Determinants of Antenatal Health Care Usage of Women's at Hossana town, in Bobicho Kebele
}

\author{
Adinew Handiso Arficho \\ Department of Statistics, Wachamo University P.O.Box 667, Hossana, Ethiopia
}

\begin{abstract}
Antenatal health care (ANC) refers to pregnancy related health care provided by a doctor or a health worker in a health facility or home. ANC is the key entry point of a pregnant woman to receive broad range of health promotion and preventive services which promote the health of the mother and the baby. This study aimed to identify the factors affecting. Antenatal health care usage of women at Hossana town in Bobicho Kebele. In order to achieve our objective descriptive statistics, cross-tabulation and logistic regression statistical techniques were used for data analysis using socio-economic and demographic variables as explanatory variables and Antenatal health care usage of women as the response variable using $\mathrm{R}$ software. The results of descriptive statistics shows that 70(42.20\%) of women were not use ANC and 96(57.80\%) were use ANC and the inferential analysis show that age of women, women's educational level, monthly average income, and material status of women, occupation of husband and utilization of accesses of health care were found to be important determinants of Antenatal health care usage of women in Hossana town at Bobicho Kebele. The result also suggested that adult, educated, married women were use ANC usage than the adolescent, uneducated and divorced and widowed women respectively. A woman's having high monthly average income use ANC than having low monthly average income. It is recommended that Governments should aware the women to use the Antenatal care usage of health service and all societies and concerned bodies must understand that education level of women and occupation of husband are the main determinant factors for the use of Antenatal care and usage of health services in our study area in Hossana town at Bobicho Keble.
\end{abstract}

Keywords: Antenatal health care usage, R software, Binary Logistic Regression

DOI: $10.7176 / \mathrm{JMPB} / 63-01$

Publication date: January $31^{\text {st }} 2020$

\section{INTRODUCTION}

Background of the study

ANC refers to pregnancy related health care provided by a doctor or a health worker in a health facility or home. $\mathrm{ANC}$ is the key entry point of a pregnant woman to receive broad range of health promotion and preventive services which promote the health of the mother and the baby. The World Health Organization (WHO) estimates that worldwide more than 529,000 women die every year from complications of pregnancy, childbirth and abortion. Ninety nine percent (99\%) of these deaths are from the developing countries. Less than $1 \%$ of these deaths occur in more developed countries making maternal mortality the health indicator with the greatest disparity between developed and developing countries.

According to World Health Organization (WHO, 2014) recommendation, for normal pregnancy minimum of four antenatal visiting (at least 20 minutes duration for each) is needed to accomplish the essential level of ANC. ANC motivate pregnant woman facing any pregnancy complication to seek advice for her problems. A study on rural Uttar Pradesh shows the likelihood of women with high ANC use delivering in an institution three times higher than for women with no ANC use (Fausdar\&Abhishek, 2005). The importance of Antenatal health care services in reducing maternal and infant morbidity and mortality has received increasing recognition since the International Conference on Population and Development (ICPD) in Cairo. The utilization of Antenatal health care is one of the important factors to reduce the incidence of maternal mortality (Mahari, 2012). WHO indicate that in developing countries, ANC also reduces maternal mortality and morbidity directly through detection and treatments of pregnancy related or inter- current illnesses (malaria, anemia and syphilis) which are prevalent and have an impact on maternal and neonatal health. Malaria in pregnancy increases the chance of maternal anemia, abortion, stillbirth, prematurely, intrauterine growth retardation and infant low birth weight. It is estimated that as many as $30 \%$ of deaths during pregnancy in Africa directly result from malaria infection and malarial anemia is estimated to cause as many as 10,000 maternal deaths each year in Africa. The burden of Malaria in pregnancy could be minimized by use of intermittent presumptive treatment (IPT) and strengthening early detection and prompt treatment of cases among pregnant women.

\section{Statement of problem}

Improving Antenatal health of population in this regards, is becoming not only an integral part of overall health 
development strategy, but also poverty reduction. The government has designed Antenatal health services program where the services are provided by private public health centers as well as international NGO's. Efforts are still being made with great intensity, however; it is proved that the need for quality Antenatal health services is not yet fulfilled. For instance, $95 \%$ of birth takes without health care facilities, while only $6 \%$ babies delivered by health professionals (CSA, 2013). This shows that the vast majority of women who give birth in Ethiopia are at risk from delivery complications and infections leading to death or serious illness. Thus, changes have to be introduced after clear identification of factors affecting the Antenatal health services.

Antenatal health, like most aspects of health in Ethiopia, is generally poor. According to the Hossana town's health bureau (Wachamo University), remarkable efforts are being made to enhance the Antenatal health of the society. However, maternal health mortality, child mortality, delivery problems and family planning problems remain to be high due to the low level of Antenatal health care service. This gap is obviously created because of some factors which have to be investigated. It is the idea that prompted that we were focus on the area of Antenatal health services. In general, the motivation behind this study is intended to address the following two major research questions

$>$ What are the factors affecting utilization of Antenatal health care services?

$>$ What is the level of women's on Antenatal health care usage services in Hossana town in Bobicho Kebele?

$>$ Are maternal health mortality, child mortality, delivery problems and family planning problems remaining to be high due to the low level of Antenatal health care service?

\section{Objective of the study}

The main objective of this study is to assess the determinants of Antenatal health care usage of women by applying binary logistic regression in case of Bobicho Keble at Hossana town.

\section{Data Source and Methodology Data Source}

The study was conducted on the determinant of antenatal care usage of women in case of Bobicho Keble at Hossana town. Hosanna town its administrative center of Hadiya zone, south nation, nationalities and people region (S.N.N.P.R). In the town there is one hospital and three health center which gives Antenatal health care usage, preventive, curative and rehabilitative service for the population. The target population for this study would be all married, divorced and widowed women whose age is between15-49 and who live between $1^{\text {st }}$ February 2018 to $1^{\text {st }}$ January 2019 in Hossana town, Bobicho keble. This study does not included unmarried women. In this study two types of variables are incorporated. These are dependent variable and independent variables that are supposed to predictors of the dependent variable.

Sample size determination is one of the first considerations in planning sample survey. The sample size determination is important because taking too large sample implies increases the precision, but waste of resources while too small sample reduces precision of estimation of population parameter or the usefulness of the results. So, it is better to determine optimum sample size, there are a number of issues. After the questionnaire was prepared directly data collection was taken place. This data was collected by self-administer questionnaire, face to face interview and researcher himself would collected directly from women of age 15-49 who live in Hossana town, Bobicho keble.

To determine the representative sample size we used the pilot survey since, there was not the previous study about assessment of Antenatal health care usage in Bobicho at Hossana town. Therefore, we would decide to use pilot survey for determining the sample. We would distribute the questions for 30 women that live in the study area. From those 18 responds yes and the rest responds no. $p=18 / 30=0.6, q=12 / 30=0.4$

So, the initial sample size will be

, $\mathbf{n}_{\mathbf{0}}==1.96^{2 *} * 0.6^{*} 0.4 / 0.07^{2=} \mathbf{1 8 8}$

$\mathrm{n}_{\mathrm{o}}=\mathrm{n}$ if $\mathrm{n}_{\mathrm{o}} / \mathrm{N}<5 \%$, Otherwise

According to Cochran (1977), $\mathrm{n}_{0} / \mathrm{N}=188 / 1452=0.1295>5 \%$, We use

$\mathrm{n}=\mathrm{no} /(1+\mathrm{no} / \mathrm{N})$

$=188 /(1+188 / 1452)=166$

$\mathrm{n}_{0}=$ the initial sample size

$\mathrm{P}=$ population proportion of women who use Antenatal health care services

(By conducting the pilot survey the proportion of women who use Antenatal health care services was 0.5 )

$\mathrm{d}=7 \%=0.07$, margin of error

$\mathrm{z}=95 \%$ of the confidence level $\left(\mathrm{z}_{\alpha / 2}=1.96\right)$

$\mathrm{n}=$ the optimum or normal sample size

$\mathrm{N}=1452$, total number of target population 


\section{Methodology of the Study}

Data processing and analysis

After the data collected, the next step would be editing, analyzing and summarizing the data in appropriate manner and also the available of the data would be transformed in to reliable and useful information with the help of statistical analysis procedure by using R software.

\section{Descriptive statistics}

Descriptive statistics refers to the techniques and methods for organizing and summarizing information obtained from the sample. It describes the importance feature of the giving data. It may be computed by the measure of central tendency and measure of variation.

\section{Inferential Statistics}

Inferential statistics is statistics that deals with making inference or conclusion about population based on data obtained from a limited number of observations that come from the population. Inferential statistics consists of estimation and hypothesis testing. For this study chi-square test of independence and Binary logistic regression analysis would be used as method of data analysis.

\section{Chi-square test of independence}

Chi-square test is method of analysis for data obtained for categorical variables. The data was in the form of counts. Chi-square test for association (independence) in a two way classification uses this procedure to test if the probability of items or subjects being classified for one variable depends on the other variable. The objective of chi-square test of independence is to test whether there is a relationship between two categorical variables or not. The data displayed by a table known as contingency table.

The mathematical form of chi- square: $\mathrm{X}^{2}$

Where: - $\mathrm{X}^{2}$ cal $=$ calculated chi-square

$\mathrm{O}_{\mathrm{ji}}=$ observed frequency in cell $(\mathrm{i}, \mathrm{j})$

$E_{i j}=$ expected frequency for cell $(i, j)$

$\mathrm{E}_{\mathrm{ij}}=\mathrm{i}^{\text {th }}$ row total $* \mathrm{j}^{\text {th }}$ column total/grand total $(\mathrm{n})$

\section{The Logistic Regression Model}

Logistic regression is used when the regressed, the dependent variable or the response variable is qualitative in nature or categorical. Qualitative response variable are either binary (dichotomous variable) or multiple category. We would use binary logistic regression in this study. The logistic regression model is a generalized linear model with random components. In a variability of regression application a response variable of interest has only two possible qualitative outcomes and therefore can be represented by binary indicator variables taking on values 0 and 1 . We shall denote this response variable by $\mathrm{Y}$ and the two possible values are 0 and 1 or by the general terminology failure and success respectively. Logistic regression allows one to predict a discreet outcome such as group membership from asset of predictor variable that may continuous discrete and dichotomous or a mixture of any of these. Consider allocation of $\mathrm{P}$ independent variables which will be denoted by a vector $\mathrm{X}=\left(\mathrm{x} 1, \mathrm{x} 2 \mathrm{x} 3------\mathrm{X}_{\mathrm{n}}\right)$

The ratio of probability success to probability of failure is $(p / 1-p)$ is odd ratio of success. Therefore, the logistic model can be written as; $p\left(X_{i}\right)=\frac{e^{\beta_{0}+\beta_{1} X_{i 1}+\beta_{2} X_{i 2}+\ldots+\beta_{p} X_{i p}}}{1+e^{\beta_{0}+\beta_{1} X_{i 1}+\beta_{2} X_{i 2}+\ldots+\beta_{p} X_{i p}}}$

Then the equation logistic regression can be written as

$\operatorname{Logit}(\mathrm{Y})=\mathrm{e}^{\mathrm{B} 0+\mathrm{B} 1 \mathrm{X} 1 \mathrm{i}+\mathrm{B} 2 \mathrm{X} 2 \mathrm{i}+\ldots . .+\mathrm{BpXpi}}$

\section{Odds Ratio}

Logistic regressions work with odds so it is necessary to define both odds and odds ratio. The odds are simply the ratio of the probabilities for the two possible outcomes. If $\mathrm{p}$ is the probability that the event will occur, then 1 $-\mathrm{p}$ is the probability that the event will not occur: 
In $2 \times 2$ tables, within row 1 the odds of success are $\operatorname{Odds}_{1}=$, and within row 2 the odds of success equal Odds 2 $=$.

The ratio of the odds from the two rows,

$$
\mathrm{P}=/=
$$

is called odds ratio. Whereas the relative risk is a ratio of two probabilities, the odds ratio $\mathrm{p}$ is a ratio of two odds.

\section{Results and Discussion}

\section{Descriptive Analysis of ANC usage}

The study was conducted on 166 women of Hossana town at Bobicho keble. From 166 women 78(47\%) women were age $15-19$ (adolescent women) and $88(53 \%)$ were respond their age $20-49(53 \%)$. The marital status of women; $52(31.3 \%), 58(35 \%)$ and 56(33.7\%) of women were married, divorced and widowed respectively. Level of education of women; 52(31.3\%), 40(24.1\%), 40(24.1\%) and 34(20.5\%) of women responds uneducated, primary, secondary and diploma and above respectively. Average monthly average income; 92(55.4\%), $31(18.7 \%), 30(18 . \%), 13(7.9 \%)$ of women were responds their monthly average income less than 560 birr, 560 1000 birr, 1001-2000 birr and above 2000 birr respectively. Occupation of husband; 69(41.6\%), 62(37.3\%) and $35(21.1 \%)$ of women responds private, governmental and nongovernmental worker husbands respectively.

Table 4.1: Summary of descriptive statistics for socio-economic and demographic variables

\begin{tabular}{|c|c|c|c|c|}
\hline \multirow[t]{2}{*}{ Variables } & \multirow[t]{2}{*}{ Categories of variables } & \multicolumn{3}{|c|}{ Status of ANC usage } \\
\hline & & Non user & User & Total \\
\hline Age of women & $\begin{array}{l}15-19 \\
20-45\end{array}$ & $\begin{array}{l}51(72.9 \%) \\
19(27.1 \%)\end{array}$ & $\begin{array}{l}27(28.1 \%) \\
69(71.9 \%)\end{array}$ & $\begin{array}{l}78(47 \%) \\
88(53 \%)\end{array}$ \\
\hline $\begin{array}{l}\text { Martial statues } \\
\text { of women }\end{array}$ & $\begin{array}{l}\text { Married } \\
\text { Divorced } \\
\text { Widowed }\end{array}$ & $\begin{array}{l}25(35.7 \%) \\
25(35.7 \%) \\
20(28.6 \%)\end{array}$ & $\begin{array}{l}27(28.1 \%) \\
33(34.4 \%) \\
36(30.55 \%)\end{array}$ & $\begin{array}{l}52(31.3 \%) \\
58(35 \%) \\
56(33.7 \%)\end{array}$ \\
\hline $\begin{array}{l}\text { Level of education } \\
\text { of women }\end{array}$ & $\begin{array}{l}\text { Uneducated } \\
\text { Primary } \\
\text { Secondary and above } \\
\text { Diploma and above }\end{array}$ & $\begin{array}{l}25(35.7 \%) \\
24(34.3 \%) \\
19(27.1 \%) \\
2(2.9 \%)\end{array}$ & $\begin{array}{l}27(28.1 \%) \\
16(16.7 \%) \\
21(21.9 \%) \\
32(33.3 \%)\end{array}$ & $\begin{array}{l}52(31.3 \%) \\
40(24.1 \%) \\
40(24.1 \%) \\
34(20.5)\end{array}$ \\
\hline $\begin{array}{l}\text { Monthly average } \\
\text { level of income }\end{array}$ & $\begin{array}{l}\text { Less than } 560 \text { birr } \\
560-1000 \text { birr } \\
1001-2000 \text { birr } \\
\text { Above } 2000\end{array}$ & $\begin{array}{l}39(55.7 \%) \\
21(30 \%) \\
8(11.4 \%) \\
2(2.9 \%)\end{array}$ & $\begin{array}{l}53(55.2 \%) \\
10(10.4 \%) \\
22(22.9 \%) \\
11(11.5 \%)\end{array}$ & $\begin{array}{l}92(55.4 \%), \\
31(18.7 \%) \\
30(18 . \%) \\
13(7.9 \%)\end{array}$ \\
\hline Occupation of women & $\begin{array}{l}\text { House wife } \\
\text { Private worker } \\
\text { Governmental worker } \\
\text { Nongovernmental worker }\end{array}$ & $\begin{array}{l}25(35.7 \%) \\
24(34.3 \%) \\
19(27.1 \%) \\
2(2.9 \%)\end{array}$ & $\begin{array}{l}27(28.1 \%) \\
16(16.7 \%) \\
21(21.9 \%) \\
32(33.3 \%)\end{array}$ & $\begin{array}{l}52(31.3 \%) \\
40(24.1 \%) \\
40(24.1 \%) \\
34(20.5 \%)\end{array}$ \\
\hline Religion of women & $\begin{array}{l}\text { Orthodox } \\
\text { Muslim } \\
\text { Protestant } \\
\end{array}$ & $\begin{array}{l}41(58.6 \%) \\
21(30 \%) \\
8(11.4 \%) \\
\end{array}$ & $\begin{array}{l}68(70.8 \%) \\
11(11.5 \%) \\
17(17.7 \%) \\
\end{array}$ & $\begin{array}{l}109(56.7 \%) \\
32(19.3 \%) \\
25(15.1 \%) \\
\end{array}$ \\
\hline $\begin{array}{l}\text { Education level } \\
\text { of husband }\end{array}$ & $\begin{array}{l}\text { Uneducated } \\
\text { Primary } \\
\text { Secondary } \\
\text { Diploma and above }\end{array}$ & $\begin{array}{l}22(31.4 \%) \\
10(14.3 \%) \\
23(32.9 \%) \\
15(21.4 \%)\end{array}$ & $\begin{array}{l}21(21.9 \%) \\
8(8.3 \%) \\
32(33.3 \%) \\
35(36.5 \%)\end{array}$ & $\begin{array}{l}43(25.9 \%) \\
18(10.8 \%) \\
55(33.1 \%) \\
50(30.1 \%)\end{array}$ \\
\hline $\begin{array}{l}\text { Occupation } \\
\text { of husband }\end{array}$ & $\begin{array}{l}\text { private worker } \\
\text { Governmental worker } \\
\text { Nongovernmental worker }\end{array}$ & $\begin{array}{l}34(48.6 \%) \\
16(22.9 \%) \\
15(15.6 \%) \\
\end{array}$ & $\begin{array}{l}35(36.5 \%) \\
46(47.9 \%) \\
20(28.6 \%) \\
\end{array}$ & $\begin{array}{l}69(41.6 \%) \\
62(37.4 \%) \\
35(21.1 \%) \\
\end{array}$ \\
\hline Media exposure & $\begin{array}{l}\text { Exposed } \\
\text { Non exposed }\end{array}$ & $\begin{array}{l}51(72.9 \%) \\
19(27.1 \%)\end{array}$ & $\begin{array}{l}27(28.1 \%) \\
69(71.9 \%)\end{array}$ & $\begin{array}{l}78(47 \%) \\
88(53.0)\end{array}$ \\
\hline
\end{tabular}

\section{Chi-square test of independence}

Test of independence are often made whenever we have a cross classification of two attributes. The Statistical model for inference requires that a null hypothesis be tested. The chi-square test of association or independence is based on the compression of observed frequencies with the expected frequencies. Chi-square test of independence for Antenatal care usage and age of women, marital status of women, monthly average income of the house hold, educational level of women and occupation of the husband. Since, the p-value is less than the level of significance (0.05) leads we reject our null hypothesis from the table 4.2 shown below. Therefore, Use 
of Antenatal care usage and age of women, marital status of women, monthly average income the house hold, educational level of women, occupation status of the husband, and utilization of health accesses has significant association.

Table 4.2, Chi-square test of independence for ANC

\begin{tabular}{llll}
\hline Variables & Pearson's chi-square & Degree of freedom & Sig.(p-value) \\
\hline Age of mother & 32.519 & 1 & 0.000 \\
\hline Marital status of women & 21.461 & 3 & 0.000 \\
\hline Average monthly income & 15.090 & 3 & 0.002 \\
\hline Occupation of husband & 11.454 & 2 & 0.003 \\
\hline Education level of women & 24.783 & 2 & 0.004 \\
\hline
\end{tabular}

\section{Logistic regression model analysis}

One of the problems of simple binary logistic regression approach is the ignorance of the probability that a collection of variables each of which is weakly associated with the outcome can become an important predictor of the outcomes when taken together. There are many variable selection procedures; among those researcher use backward elimination procedure to select the best variables of the model. Backward elimination is the procedure of selecting variable starting from regressing all variables at a time and removes the variable which has minimum Wald test or maximum p-value as compared to the level of significance Table 4.8; Multiple logistic regressions model analysis

\begin{tabular}{|c|c|c|c|c|c|c|c|c|}
\hline \multirow[t]{2}{*}{ Variables } & \multirow[t]{2}{*}{ B } & \multirow[t]{2}{*}{ S.E. } & \multicolumn{2}{|c|}{ Wald } & \multirow[t]{2}{*}{ Sig. } & $\operatorname{Exp}(B)$ & \multicolumn{2}{|c|}{ 95.0\% C.I.for EXP(B) } \\
\hline & & & & & & & Lower & Upper \\
\hline Adult women & 2.684 & .522 & 26.439 & 1 & $.000^{*}$ & 14.649 & 5.265 & 40.756 \\
\hline $\begin{array}{l}\text { Marital status } \\
\text { of women }\end{array}$ & & & 6.321 & 2 & $.042 *$ & & & \\
\hline Divorced & 2.805 & 1.313 & 4.559 & 1 & $.033^{*}$ & 12.520 & 13.954 & 43.770 \\
\hline Married & 2.559 & 1.373 & 3.475 & 1 & $.002 *$ & 22.926 & 15.441 & 32.561 \\
\hline Level of income & & & 11.310 & 3 & $.010 *$ & & & \\
\hline $560-1000$ & -.807 & .621 & 1.693 & 1 & .193 & .446 & .132 & 1.505 \\
\hline $1001-2000$ & 1.914 & .683 & 7.858 & 1 & $.005^{*}$ & 6.781 & 1.779 & 9.855 \\
\hline Above 2000 & .892 & 1.217 & .537 & 1 & .464 & 2.440 & .225 & 26.525 \\
\hline Occupation of husband & & & 13.758 & 2 & $.001 *$ & & & \\
\hline Governmental worker & 1.436 & .525 & 7.486 & 1 & $.006^{*}$ & 4.202 & 1.503 & 11.751 \\
\hline Non governmental worker & -.969 & .617 & 2.465 & 1 & .116 & .379 & .113 & 1.272 \\
\hline Education level of women & & & 9.036 & 2 & $.011 *$ & & & \\
\hline Uneducated & -3.853 & 1.336 & 8.310 & 1 & $.004 *$ & .021 & .002 & .291 \\
\hline Primary educated & -1.783 & 1.370 & 1.695 & 1 & .193 & .168 & .011 & 2.463 \\
\hline
\end{tabular}

\section{Interpretation of estimated parameter}

The odds of using Antenatal care usage among adult women(age 20-45) was 14.649 times higher than that of the odds of using Antenatal care usage among the adolescent women. Or participants using Antenatal care usage were 14.649 times more likely to adult women (age 20-45) as compared to the adolescent women (age 15-19), controlling the effect of other variables in the model, the odds of using Antenatal care usage among divorced women was 12.52 times higher than that of the odds of using Antenatal care usage among the widowed women (reference group). Similarly, participants using Antenatal care usage were 22.926 times more likely to Married women as compared to widowed women, keeping the effect of other variable in the model.

The odds of using Antenatal care usage among uneducated women was 0.021 times lower than that of the odds of using Antenatal care usage among secondary and above educated women (reference group). That means participants using Antenatal care usage were 0.210 times less likely to uneducated women as compared secondary and above educated women (reference group), keeping the effect of other variable in the model.

The odds of using Antenatal care usage among public(governmental) worker husbands was 4.202 times higher than that of the odds of using Antenatal cares usage among private worker husbands (reference group). Or participants using Antenatal care usage were 4.202 times more likely for public (government) worker husbands as compared to private worker husbands (reference group), keeping the effect of other variable in the model. Finally, the odds of using Antenatal care usage among women having monthly average income 1001-2000 birr was 6.781 times higher than that of the odds of using Antenatal cares usage among women having monthly average income less than 560 birr (reference group). This indicates participants using Antenatal care usage were 
6.781 times more likely for women having monthly average 1001-2000 birr as compared to women having monthly average income less than 560 birr, keeping the effect of other variable in the model.

Test of goodness of fit of the model

Table 4.9, Hosmer and Lemeshow Test

\begin{tabular}{|c|c|c|}
\hline Chi-square & $\mathrm{df}$ & Sig. \\
\hline & 8 & .691 \\
\hline
\end{tabular}

Hosmer-Lemeshow test is used to assess the overall goodness of fit of the fitted model. It is performed by dividing the predicted probabilities into deciles (10 groups based on percentile ranks) and then computing a Pearson chi-square that compares the predicted to the observed frequencies (in a $10 \times 2$ table). The P-value is 0.691 for the Hosmer-Lemeshow goodness of fit test is greater than 0.05 , we will not reject the null hypothesis that there is no difference between observed and model predicted values, implying that the model estimates are adequate to fit the data at an acceptable level.

The Likelihood ratio statistic

\begin{tabular}{|l|l|l|}
\hline-2 Log likelihood & Cox \& Snell R Square & Nagelkerke R Square \\
\hline $131.222^{\mathrm{a}}$ & .435 & .585 \\
\hline
\end{tabular}

$\mathrm{G}^{2}=-2\left(\mathrm{~L}_{\mathrm{o}}-\mathrm{L}_{1}\right)$ given in the previous chapter. The $\mathrm{L}_{\mathrm{o}}$ for restricted (smaller) model is $=131.222+94.814=$ 226.036 and that of $\mathrm{L}_{1}$ for full (larger) model is 131.222 which implies a model chi square of 94.814 with (pvalue $=0.000)$ which signifies significant decreases in deviance there by implying a good fit of the model.

\section{Conclusion and Recommendation Conclusion}

The utilization of Antenatal care is one of the important factors to reduce the incidence of maternal mortality. The main objectives of this study were to determinant of utilization of modern Antenatal health care services in Hossana town at Bobicho Keble. In this study the major factors for ANC services include: age of mother, marital status of women, education level of women, average monthly income, and occupation of husband and access of health services. On the other hand, in this study we conclude that ANC care and usage of health care is not significantly related with occupation of women, religion, and education level of husband and media exposure. Adult women (age 20-45) were use Antenatal care usage of health service and Married women were use Antenatal care usage of health service than divorced and widowed women. Diploma and above educated women were use Antenatal care usage of health service than uneducated, primary educated and secondary educated women. Finally women's having monthly average income of above 2000 birr were use Antenatal care usage of health service than having monthly average income of less than 560 birr ,560-1000 birr and 1001-2000 birr.

\section{Recommendation}

This paper tries to identify the factors affecting Antenatal care and usage of health services. And the following recommendations are made for health worker and the community. Governments should aware the women to use the Antenatal care usage of health service in Hossana town at Bobicho keble. And also the government and other concerned bodies should make efforts to expand general community based education so that women can have better access to information concerning Antenatal care usage of health services.

\section{REFERENCES}

Agresti, A. (2002), Categorical Data Analysis. Wiley Interscience, NewYork.

Belsley D. and Welsch R. (1980), Regression Diagnostics:Iden Belsley

Chandiok, N. 2006, Determinants of ANC utilization in rural areas of India, J Obstetric Gynecol India January/February.

Cochrane S. (1979). Fertility and education. Baltimore: The John Hopkins University Press.

Coeytaux F.,Bingham D. , Langer A. (2011). Reducing maternal mortality, global imperative. Contraception. ;83-95-5

Fausdar R. (2006), Is ANC effective in improving maternal health in rural Uttar Pradesh Evidence from district level household survey, international.

Gubhaju B. (2001) Women's status, household structure and utilization of maternal health services in Nepal.Asia Pacific Population Journal ,16(1):23.

Hossana town, health office (2016), planning for provision health services.

Hosmer. W and Lemeshow .S (2000), Applied Logistic Regression. 2ndEdn. John Wiley and Sons, New York.

Kamal, S. (2009): Factors affecting utilization of skilled maternity care services among married adolescents in Bangladesh, Asian Population Studies, 5:2, 153-170..

Mahari, K. (2012) , Determinant factors affecting utilization of maternal health care services in rural Ethiopia , 
Addis Ababa Ethiopia, Addis Ababa University.

Marge,K, et, al (2010), Under-users of antenatal care: a comparison of non-attenders and late attainders for antenatal care, with early attendees. Social Science and Medicine 40: 1003-1012.

Rawlings O, Pentula G, Dickey A. (1998), Applied regression analysis: Department of Statistics, North Carolina State University.

WHO, (2014), maternal mortality in 2015: Estimates developed by WHO.

Zenebe, M. (2011), Socio demographic factors affecting antenatal care service utilization among women in the wolaita zone. 